\title{
A cooperativa sem degredados: uma esquizoanálise da sua promessa de felicidade
}

(The cooperative without outcasts:

A psychoanalysis of its promise of happiness)

Guilherme Gomes Krueger ${ }^{1}$

Instituto dos Advogados do Brasil (Brasil)

Sumario: 1. Introdução e propedêutica. 2. A desterritorialização do direito cooperativo pelos sistemas peritos. 3. Um paradigma realista para a participação econômica do sócio e a gestão democrática da cooperativa. 4. Uma esquizoanálise do paradigma. 5. À guisa de conclusão. 6. Referências bibliográficas.

Summary: 1. Introduction and propaedeutics. 2. The deterritorialization of cooperative law by expert systems. 3. A realistic paradigm for the member economic participation and the democratic management of the cooperative. 4. A schizoanalysis of the paradigm. 5. As a conclusion. 6. References.

Resumo: Um contraponto possível ao postulado continente da principiologia da $\mathrm{ACl}$ faz emergir possibilidades literárias marginais face aos princípios da participação econômica do cooperado e da gestão democrática da cooperativa, quando impregnada da pragmática nômade proposta por Deleuze e Guattari, conquanto o contexto contemporâneo é pensado a partir da plasticidade do bem estar entre a ética e a estética, fenômeno evidente, quando se aborda a felicidade como o fim da vivência em cooperativas.

Palavras chave: Cooperativa - felicidade - filosofia contemporânea.

Abstract: A possible counterpoint to the continent's postulate of ICA's principles leads to the emergence of marginal literary possibilities in the face of the principles of co-operative member economic participation and its democratic control, when impregnated with the nomadic pragmatics proposed by Deleuze and Guattari, while the contemporary context is thought from the plasticity of well-being between ethics and aesthetics, an obvious phenomenon, when one approaches happiness as the end of the experience in cooperatives.

Keywords: cooperative - happiness - contemporary philosophy.

1 Instituto dos Advogados do Brasil, Comissao de Filosofia do Direito. Correo electronico: guilherme@gomeskrueger.adv.br 
O profissional quando erra, corrige o erro com um acerto. O amador quando erra, corrige um erro com outro erro. O profissional acumula com a experiência. O amador se dispersa com a experiência (...) A obra do amador é uma orquestração dos seus melhores erros (....) com isso ele contribui para o acerto do resto dos artistas do mundo, inclusive os profissionais.

Arthur Omar, Antropologia da face gloriosa

\section{Introdução e propedêutica}

Tal como ela é exposta corriqueira acerca das cooperativas, a principiologia tem por referência incontornável a literatura produzida pela Aliança Cooperativa Internacional. Bastante evidente a sua ancoragem na tradição do pensamento anglo-saxão. É sistemática, continente, programática e construida de como algo consensual entre a normalidade e a normatividade em contextos sócio-econômicos dados. Ou seja, transita entre o que descreve e o que prescreve a partir de uma pragmática construída por consensos que refletem uma faticidade histórica e uma funcionalidade hoje rumo ao futuro².

Um contraponto possível ao postulado continente da principiologia da $\mathrm{ACl}$ faz emergir possibilidades literárias marginais face aos princípios da participação econômica do cooperado e da gestão democrática da cooperativa, quando impregnada da pragmática nômade proposta por Deleuze e Guattari, conquanto o contexto contemporâneo é pensado a partir da plasticidade do bem estar entre a ética e a estética, fenómeno evidente, quando se aborda a felicidade como o fim da vivência em cooperativas ${ }^{3}$.

Desde Ser e Tempo, escrito na década de 20 por Martin Heidegger, é possível uma cisão ao se pensar um conceito ${ }^{4}$. Em aulas de pensamento contemporâneo num curso de filosofia, se costuma afirmar que,

2 «Notas de Orientación para lós princípios cooperativos.(2015)», ALIANZA COOPERATIVA INTERANCIONAL, acessado em 22 de maio de 2018. https://ica.coop/ sites/default/files/publication-files/guidance-notes-es-2107251738.pdf.

3 «É preciso fortalecer o diferencial da atividade cooperativista, seguir os valores e os princípios do cooperativismo e, exercer e comunicar para toda a sociedade a capacidade do cooperativismo de gerar felicidade para os cooperados.», OCB, acessado em 22 de maio de 2018. http://www.ocb.org.br/arquivos/MapaEstrategico/final_mapa_ estrategico_sistema_21_09.pdf

4 15. ${ }^{a}$ Ed. Trad. Marcia Sá Calvalcanti Schulback. (Petrópolis : Vozes, 2005). 
até Heidegger, ser e ente eram sempre idênticos. Os entes eram distintos entre si nas relações entre o universal e o individual. Depois dele, ser e ente podem seer ${ }^{5}$ distintos. O existente não é aquilo que seja idêntico a si mesmo.

Tipo, escolha é escolha; razão é razão. A participação econômica do cooperado e a gestão democrática da cooperativa, sendo princípios universais de identidade cooperativa, também são linguagem do ser cooperativo; uma apropriação histórica que acontece nas peripécias e vicissitudes do pensamento ${ }^{6}$.

5 Heidegger criou diversas expressões para imprimir sua analítica-existencial. Uma delas era recorrer à variante arcaica seyn para designar sein. Heidegger volta e meia referenciava os seus textos nos de Hölderlin, que, em 1795, escreveu Urtheil und Seyn [Juízo e Ser]. Isso é assunto para um jantar entre tradutores e professores de filosofia para o qual, se formos convidados, precisaremos de um pequeno manual de filosofia para sobrevivência à um papo-cabeça. Aqui, adoto arbitrariamente a transliteração "seer» para designar o ser existencial (ser, acontecendo) que se distingue do ser entificado (ser, sendo).

6 «Uma coisa, porém, é apreender imediatamente uma imagem como imagem, outra é formar pensamentos sobre a natureza das imagens em geral. O único meio de constituir uma teoria verdadeira da existência em imagem seria limitar-se rigorosamente a nada afirmar sobre esta que não tivesse diretamente sua fonte numa experiência reflexiva. É que, na verdade, a existência em imagem é um modo de ser de apreensão muito difícil. Para isso, é preciso contenção de espírito; é preciso, sobretudo, livrar-se de nosso hábito quase invencivel de constituir todos os modos de existência segundo o tipo da existência física.» Jean-Paul Sartre, A imaginação. Trad. Paulo Neves. (Porto Alegre: L\&PM, 2008).

p. 9. O problema se constata em Kant no modo em que pensou a conformação e a percepção da realidade. A imaginação para Kant é uma faculdade de formar imagens e representações. Tanto dos objetos sensíveis como os racionais (intelectuais). Embora possa apresentar imagens originais, para Kant, a imaginação nunca cria, pois sempre é possível encontrar a origem das imagens que a imaginação produz nos sentidos. Trata-se portanto de capacidade associativa (fluxos), plástica (compositiva ou onírica), de afinidade, designativa ou distintiva, mas não poiética (no sentido de que os conceitos preexistem à imaginação, o que permite identificar o delírio do real). A imaginação é a faculdade responsável pela comunicação entre as faculdades, e o seu caráter antropológico garante a universalidade intuitiva dos juízos do entendimento. No entanto, a imaginação estética, descrita como a experiência do sublime, irá conformar uma estrutura diferente daquela do conhecimento e aponta para uma fronteira. Nesta fronteira, pode-se estabelecer sua controvérsia com os escritores identificados com a expressão Sturm und Drang [Tempestade e ímpeto] para os quais a imaginação manifesta criatividade. Para esses autores contemporâneos, como Goethe, o estado de espírito ocupa uma posição central que a razão encontra no pensamento de Kant. Não é acaso que esses autores serão referências para artistas (irmãos Grimm, Wagner), conquanto juízes e juristas irão se interessar por Kant. Mas, todos têm por pressuposto metanarrativas essencialmente racionais e universais. 
Bom, antes de Heidegger, isso já era insinuado na obra de Nietzsche ${ }^{7}$. Mas, não sob uma perspectiva ontológica, própria do Heidegger. E sim sob uma perspectiva estética ${ }^{8}$. Voltaremos a essa perspectiva oportunamente. Importa agora apresentar umas poucas implicações da cisão entre ser e ente. Ou melhor, o ente como sendo ele mesmo e como linguagem ${ }^{9}$. Estão em jogo aqui são as relações entre pensar, ser e acontecer uma cooperativa. Está claro então que esta introdução é isso mesmo: um prolegômeno com ares propedêuticos.

Para alguém se definir como pragmático, ou quem aprecia a si mesmo percebendo-se como uma pessoa que se conscientiza por meio de estudo e leituras para resolver problemas práticos, os conceitos apresentam acontecimentos. Ou seja, o conceito é um reflexo do acontecimento. A verdade do conceito é a sua adequação ao que acontece. E o que acontece? É realidade.

Outra coisa é pensar o conceito, qualquer conceito (e cooperativa é um conceito aqui) como ele próprio um acontecimento. Aí, para além de Heidegger e de Nietzsche, precisamos chegar nalguns franceses. Nos franceses que são identificados a partir da partícula «pós»: pós-modernos ou pós-estruturalistas. Esses pensadores a que me refiro (Lyotard, Foucault, Derrida, Deleuze e Guattari) têm em comum isso: há no espaço econômico e social uma dimensão inflexiva no limiar da cognição e da reflexão. Aí, o devir. É uma dimensão disfuncional. Eis que sua existência é radicalmente originária nessa dimensão. Ser é, enquanto for; assim sendo, é e não é. É realmente possível então suspeitar de encadeamentos longos da razão em qualquer argumentação.

Se penso que o real é a realidade de uma realização, ou seja a participação econômica do sócio de uma cooperativa, postularei que a ver-

7 «Das cinzas do sujeito clássico, emerge em seu esplendor a dimensão do corpo, em cujas fronteiras se oculta, por sua vez, o despertar vindouro do além-do-homem, viabilizado e preparado pela atuação de dois operadores nucleares: a criação e a desmedida.» Alberto Marcos Onate, Entre eu e si ou a questão do humano na filosofia de Nietzsche. ( Rio de Janeiro : 7 Letras, 2003.), 15.

8 Defino assim a estética: engenhosidade do encantamento. Taí uma boa tirada para aquele jantar a que me referi na nota 4.

9 Preciso, no entanto, fazer uma ressalva aqui. Recorrente que atores da comunidade acadêmica do Direito façam referência a uma expressão genérica —a virada linguística - para empreender mixagens temerárias de tradições distintas de pensamento - de Wittgenstein e Rorty a Foucault e Derrida. O problema é que esses textos costumam confundir erudição com consistência filosófica. Para que uma correlação de tradições distintas de pensamento não descambe para uma verborragia biruta, ainda que erudita, é necessário voltar ao seu tronco comum. Provavelmente, serão necessárias leituras de gregos clássicos. Em todo caso, demanda uma vida de dedicação. Ao Direito, só de passagem. Porque a dedicação será ao pensamento. 
dade acerca dessa participação é a realidade realmente realizada como demonstração dela. Mas, para esses franceses a que me referi, a realidade é a realização do real. Se eu tiver que apresentar isso num curso didático, vou começar com exercícios de Gestalt para ilustrar o que estou dizendo aqui ${ }^{10}$. Trago algumas lições de Cornelius Castoriadis sobre criação humana, ministradas no ano letivo de 1986/1987:

Uma concepção funcionalista supõe que todas as instituições sociais e todos os atos dos indivíduos que compõem uma sociedade existem para realizar uma determinada função. (....) Todas as instituições de uma sociedade realizariam uma determinada função e os indivíduos seriam treinados para realizá-las. Todas essas funções devem ser coordenadas tendo em vista alguma coisa - obriga-se, portanto, a colocar uma finalidade suprema a cujo serviço foram colocadas, têm lugar, desenvolvem-se todas essas funções. (....) Sob pretexto de cientificidade, somos então obrigados a admitir uma finalidade última - que está suspensa no ar e em nada explica o que se passa na sociedade. ${ }^{11}$

Para Castoriadis, as funções no imaginário social instituinte, de certo modo, são tanto um sucedâneo como um supedâneo dos mitos: uma compensação para as impotências reais do homem ${ }^{12}$. Tanto o mito, como a função formam, arranjam e domam as forças/fatores da natureza/determinação na imaginação ${ }^{13}$, porque tal domínio não pode

10 «Freud said, marvellously: the death drives work in silence in the uproar of Eros. Eros and the death drive incompossible, are indissociable. And so it is, all things being equal, for the passage of intensities and the surface of inscription. For this operates like memory, preserving the passage, it is that by means of which effervescence is recorded and conserved, it is the means of transforming the singular sign of nothing, which is intensity, into terms of presencelabsence, the position, and thereby the value, of which will be assigned as the presencelabsence of other terms, functioning as their recording, their place in a form, Gestalt, or composition. The surface of inscription is then the means of recording. And from the means of recording to the means of production there is but one thing to do, which the despot accomplishes, as Deleuze says, which the great Gestaltist accomplishes. We well know that this surface is at the same time, indiscernibly, the libidinal skin 'engendered' by the mad bar and the wise flat sheet of the account book.» Jean-François Lyotard, Libidinal Economy. Trad. Iain Hamilton Grant. (Bloomington : Indiana University Press, 1993), 18.

11 Sujeito e verdade no mundo social-histórico. Trad. Eliana Aguiar. (Rio de Janeiro : Civilização Brasileira, 2007), 25.

12 P. 26.

13 «O que se chama de racionalidade e razão no mundo moderno (....) é o conídico tomado por si mesmo e transformado em significação imaginária social central da sociedade.» (p. 44) Conídico é um neologismo criado por Castoriadis para designar a dimensão conjuntista-identitária do real. «Como seria possível construir uma espécie 
se estabelecer na realidade «pois o mundo humano é caracterizado desde o início por algo que cria um abismo com relação à naturalidade e à animalidade — quaisquer que sejam, aliás, as relações que ele mantém com estas últimas - ou seja, a aparição, nos humanos, do imaginário tanto no nível do ser humano no singular (imaginação) quanto no nivel social (imaginário social ou imaginário instituinte)» ${ }^{14}$. Na predominância da imaginação, acontece a desfuncionalização da psiquê humana: o aparecimento dos desejos contraditórios, dos dilemas angustiantes ${ }^{15}$. Uma disjunção com a qual a humanidade desapareceria por inaptidão à vida biológica. Mas, a imaginação intervém de uma maneira muito própria e construtiva pelo (e, não no) ser humano ${ }^{16}$ -

de esqueleto ideal-típico dos atos tal como ele seria se o agente fosse, como diz Weber, zwecktrational, isto é, racional quanto aos meios em relação ao fim, instrumentalmente adequado. Um usuário veneziano do sec XVI quer ganhar dinheiro (....); mas, nas condições em que ele se encontra no sec. XVI, sendo o usurário em questão racional, com os conhecimentos que tem, nas circunstâncias que são as suas, ele fará isso, aquilo e aquilo outro. Ora, o que vemos em O mercador de Veneza, de Shakespeare? Que Shylock escolhe perder 3 mil ducados para conseguir, certamente não uma libra de carne, mas a pele de alguém que ele detesta (com toda razão, aliás). Ele sai então do comportamento zweckrational, ele não é o usurário ideal típico. Tal caso não colocaria dificuldades para a concepção de Weber: Posso compreender que esse usurário seja levado por sua paixão contra Antônio a ponto de não agir como um usurário racional. É a paixão que entra em jogo» (p. 39). A dimensão conídica é ambígua. Permite designar, organizar e operar - potência da representação e referência, e portanto a atualidade da significação, codificação e decisão. Mas, também carrega consigo a reunião, a adaptação, a fabricação, no sentido da derivação e da potência como realização.

14 P. 28.

15 Isso acontece porque no ser humano, na preponderância da imaginação, o prazer de órgão se dissocia do prazer de representação. A sublimação é a evidência da dissociação. "Capacidade de sublimar: capacidade da psique de investir objetos colocados social-historicamente, donde, instituídos ou podendo sê-lo, donde valorizados social-historicamente, ou podendo sê-lo, não lhes conferindo nenhum prazer de órgão. Essa capacidade de sublimação é um sine qua non da existência do indivíduo como indivíduo social. Ela é pressuposto para que haja linguagem ou, mais exatamente, por parte do sujeito, atividade da palavra. O sujeito da linguagem não é um sujeito pulsional. Falar é uma atividade sublimada: não proporciona nenhum prazer de órgão». pp. 144-145.

16 Para compreender o que ali vai afirmado, é preciso mencionar o passo inaugural dado por Edmund Husserl em situar a transcendência além da subjetividade e aquém da objetividade no limiar do corpo humano como campo fenomenológico da situação. "Husserl se pergunta sobre dados de cor que têm relação com o mundo externo; depois sobre dados de prazer e de dor que, pelo contrário, fazem referência ao mundo interior. Todos eles são dados da sensibilidade. Portanto, a sensibilidade tem uma vertente ao exterior e outra ao interior. Como nomear esses dados? Poderíamos chamar de sensibilidade, porém, na tradição, esse termo fazia referência, sobretudo, aos primeiros, ou seja, aos dados de cor. Mas, Husserl quer falar de um 
a instituição da sociedade. "[O] exame de cada sociedade, inclusive a nossa, mostrará que todas elas submetem o conjunto das instituições funcionais a finalidades não funcionais, mas imaginárias e dependentes das significações sociais do conjunto considerado (....) a sociedade mantém-se unida em função dessas significações imaginárias sociais e é por elas que, em geral, está pronta para viver e morrer» ${ }^{17}$. Castoriadis postula que a psique não cria linguagem ou instituições. Há a necessidade de pensar outro nível de ser humano —-social-histórico- como um campo de criação e destruição de significações imaginárias que surgem a partir do momento em que existe uma multiplicidade de seres humanos em coexistência e convívio, inobservável em suas origens, eis que ser humano então é desde sempre ser socializado ${ }^{18}$.

O imaginário social ${ }^{19}$, ao se relacionar com a imaginação, se movimenta: ao construir, também se retira, de todo ou em parte, gradual ou em irrupção, das significações imaginárias; as desinveste, as destitui, esvaziando-Ihes a validade ou autenticidade. Só que essa destitui-

território unitário, que tem duas faces. Então, em vez de usar o termo sensibilidade, utiliza o termo grego hylé que significa matéria. (....). Os dados de prazer e de dor são como a madeira com a qual fazemos uma estátua. O que dá a forma? O sentido. Que sentido têm esses dados? Esse sentido é intencional. Quer dizer, eu quero algo, dou um sentido para um fim, uma finalidade. Husserl nomeia este sentido como uma nova palavra: noesis, noese. (....). Porque a palavra grega nous significa sentido, intelecto, significado. Ele diz que nossa experiência fundamental tem um aspecto hilético —dados de cor e prazer- e , depois, também, um sentido. (....) Eu gosto da cor branca —os dados de cor branca - então compro uma roupa branca ou pinto a parede de branco, isto é, realizo uma ação finalizada; avalio aqui fica legal o branco: este é o aspecto noético. Angela Ales Bello. Trad. Miguel Mahfoud e Marina Massimi. Fenomenologia e ciências humanas. (Bauru : Editora da Universidade do Sagrado Coração, 2004), 216-218. Com Husserl, há uma mudança significativa do conceito de nada. Nada deixa de ser ausência absoluta para ser horizonte de indistinção. Ou seja, ao invés de um jogo entre presença/ausência, um jogo comum tanto na metafísica como na epistemologia, a fenomenologia joga com o aparecimento/desaparecimento - a consciência como acontecimento. A hilética/noética de Husserl é esse jogo, mas ainda conserva algo comum com Kant: a transcendentalidade, que se manifesta em uma mathema (uma totalidade cognoscível).. Husserl foi orientador de Heidegger, que do jogo aparecimento/desaparecimento derivou um outro jogo de ser e não ser em que presença e ausência deixam de ter significados opostos, mas paradoxalmente concomitantes no existente: eis o sentido de tempo em sua obra Ser e tempo. Para isso, Heidegger criou uma linguagem que impossibilita a mathema na totalização do existente. A totalidade é poiesis. Portanto, incognoscível a priori. Husserl, um matemático por formação, manifestou desconforto: para ele, Heidegger foi longe demais.

17 P. 33.

18 P. 49.

19 «O imaginário social como instituinte constrói significações imaginárias sociais (....). Estas significações imaginárias sociais são encarnadas em e instrumentalizadas por instituições. « (p. 34). 
ção não acontece necessariamente com a criação de outras instituições que tomariam seu lugar ou de outras significações. A possibilidade de acesso a essas duplas erráticas criação/destruição, instituição/destituição é que se pode afirmar contemporaneidade ${ }^{20}$.

Para quem costuma pensar, escrever e realizar conforme o pragmatismo, o funcionalismo ou o criticismo, qualquer referência ao inconsciente remete direto à subjetividade. Aí, fica fácil, quase necessário um apego à objetividade. Sejamos objetivos para resolver nossos problemas, não é mesmo? Aqui então chego no magma imaginário. Ele não é subjetivo. Nem objetivo. Mas, mesmo assim, tem a sua lógica ${ }^{21}$. Voilà! A lógica do magma, junto com a imaginação radical (este um exercício da subjetividade por excelência) ${ }^{22}$, do histórico-social ${ }^{23}$ e das significações imaginárias sociais ${ }^{24}$, define algo que permanece indefinível numa abordagem tanto pragmática como funcional ou mesmo crí-

20 P. 24.

21 Não se trata de uma lógica formal, mas hilética. A partir do que chama conídico, Castoriadis estabelece uma vivência constitutiva de um mundo para-si em relação ao mundo-assim, vivência presente desde um vírus até o ser humano. No magma aparece a predominância humana da imaginação (em relação à dimensão conídica da percepção e do comportamento) em constituição de um mundo para-si e nele as conjunções são quantitativamente ilimitadas. Ainda que se perceba diferenças magmáticas, não se conhece divisões analíticas no interior do magma. Portanto, sempre que se decomponha do magma conjuntos identitários histórico-sociais, ainda assim restará magma. Mas, nada há além do magma, senão sua superfície, que são as significações imaginárias sociais.

22 Criação de um fluxo constante de representações, desejos e afetos..É radical no sentido de impulsão à criatividade. O radical aqui acentua o caráter da poiesis no pensamento de Castoriadis. As demandas de socialização canalizam esses fluxos.

23 Dimensão indissociável entre a subjetividade e a sociedade como mundo de significações. A autonomia corresponde à possibilidade de questionamento dessas significações, o que se dá como possibilidade de alterar o que sequer é tido como questionável num dado aqui e agora.

24 Não se trata de uma representação ideal de um mundo real, mas uma positivação originária do imaginário social instituinte como instituição histórica-social. São significações sem referente, mas são referências para o instituído. Podem ser implícitas, mas sempre são apropriações histórico-sociais de representações, afetos e ações. Essas significações não são sujeitas a uma lógica de nexo causal ou pragmática, mas podem ser acessadas nas próprias instituições - como uma apropriação (um certo sentido de padrão) que acontece num dado aqui e agora do representar, do afetar e do agir. Estamos diante da dignidade como valor-fonte do Direito Constitucional do Estado Democrático de Direito. Mas, o aborto como matéria de Direito Constitucional /penal coloca em questão o bem jurídico como significação histórico-social: toda vida humana é digna de ser vivida, ou é a vida humana alguma significação da personalidade? Em jogo aqui a autonomia humana como a fonte da dignidade e a dignidade como fonte axiológica. «Todas as leis se equivalem? Será essa lei justa? Qual é a lei justa? O que é justiça? A partir daí uma outra atitude surge, distinguindo entre as situações de fato. (....)», 165. 
tica. Não são os conceitos como acontecimentos exatamente abordagens opostas ou complementares aos conceitos como apresentações de acontecimentos. Não evoco simplesmente alguma interdisciplinariedade entre o Direito e a Comunicação ou Literatura. Em todo caso, aponto para uma autopoiese do Direito Cooperativo ${ }^{25}$.

O magma de significações imaginárias é um fenômeno social. No magma, numa composição indivisível e dinâmica, há explicações e argumentações acerca dos diferentes conceitos principiológicos e as múltiplas abordagens epistemológicas aos problemas e desafios postos para a ordem econômica no atual estado das artes. Mas, elas estão contidas numa complexidade inconsciente ${ }^{26}$. Isto é, o Direito Cooperativo é magma imaginário nas explicações, nas recordações, mas também nas narrativas e nos totens que toda normatividade carrega. Tenha em mente então que a distinção entre cooperativa e empresa é como o movimento de placas tectônicas. Os conceitos como apresentações do que acontece são como crostas, cujos elementos constituintes se distinguem quando submetidos a uma reflexão cognitiva rigorosa e são verdadeiros, se funcionam. Mas, sem qualquer prejuízo à funciona-

«Para a psique, considerada em si mesma, a inclinação natural e o modo natural do investimento sublimado, como do investimento em geral, é o investimento rígido. É a cessação do questionamento, um repouso, uma estabilidade, uma repetição. A esse respeito, é a sociedade heterônoma, com instituições que não devem nem podem ser questionadas e a rigidez dos investimentos correspondentes que se evidencia igualmente como modo de ser normal ou mais provável da instituição humana. Pois ela satisfaz a tendência da psique, uma vez encontrado um ponto de investimento, a se manter nele, a repeti- lo; ela corresponde à detestação que a psique experimenta pelo que é incerto. (....) Isso só pode ser mudado a partir do momento em que emergem na história instituições colocadas de outro modo, o modo do que pode ser questionado e é a existência de tais instituições que permite, em escala social, que os investimentos sublimados tornem-se eles próprios lábeis, não rígidos, transformáveis.» ,166-167.

25 Poder-se-ia escrever esta introdução a partir da ontologia da realidade, obra de Humberto Maturana,caminho percorrido por Niklas Luhmann ou Günter Teubner, recorrentemente citados nas academias de Direito. Mas, me pareceu interessante manter-me estritamente circunscrito ao ambiente acadêmico francês no presente opúsculo. Em todo caso, bastante aqui registrar este comentário: «a teoria da autopoiese não busca o fundamento do direito; fornece um modelo de organização do direito positivo. Esse modelo é a auto-organização de uma ordem sistêmica. Tal postura não deixa de evocar a metáfora proposta por $R$. Dworkin do romance escrito em corrente - aí a regra de ouro é respeitar o princípio da unidade do todo, aquela que constitui a corrente do direito. Simone Goyard-Fabre, Os fundamentos da ordem jurídica. Trad. Claudia Berliner. (São Paulo : Martins Fontes, 2007), 224-225.

26 Plexo: rede ou entrecruzamento imbricado. Complexo então e entrecruzamento imbricado de redes/sistemas/padrões distinguíveis entre si. 
lidade e à faticidade, mesmo assim, eles erram no movimento magmático. No magma, e não na frieza da reflexão, o devir.

Erro de introdução? Sim, essa introdução não nega sua natureza errática. Mas, nem por isso perdida de todo.

\section{A desterritorialização do direito cooperativo pelos sistemas peritos}

Via de regra, uma participação econômica de um sócio de cooperativa tem um sentido próprio. O sentido dela é o seu incentivo em termos de custos de transação. Quando uma atividade econômica é apresentada com este sentido, sua abordagem tende a idealizações formais. Modelos pragmáticos são validados pelo seu rigor cognitivo, portanto instrumentos de eficácia para análise e dedução. Próprio da tradição moderna anglo-saxã, a interface entre a Economia e o Direito se apropria do notável desenvolvimento da lógica nos últimos 150 anos, quando surgiram diferentes sistemas lógicos, que mantiveram em comum uma linguagem simbólica e formal. A lógica como linguagem deu suporte ao postulado da existência de uma cognição universal; um postulado que alinha gente das estaturas históricas de Aristóteles, Kant, Peirce e Habermas.

Vou escolher o Peirce para correlações, haja vista a sua notável influência difusa na produção intelectual das mais renomadas universidades americanas. Para situá-lo historicamente, bastante mencionar aqui que ele, ainda jovem, lecionou em Harvard logo após a Guerra Civil Americana.

A partir de Peirce, por sua contribuição colossal, quando vinculou a lógica à semiótica, podemos compreender que a literatura usual sobre a participação econômica do sócio na cooperativa sempre se apresenta com marcada determinação de significados para a racionalidade política e jurídica. Posso aqui recorrer a um sugestivo texto de Peirce, How to make our ideas clear, publicado em 1878, para referenciar o que afirmo acerca do texto comentado:

Aparentemente, portanto, a regra para alcançar o terceiro grau de clareza de apreensão é a seguinte: considerar que efeitos -imaginavelmente possíveis de alcance prática - concebemos que possa ter o objeto de nossa concepção. A concepção desses efeitos corresponderá ao todo da concepção que tenhamos do objeto27.

27 Semiótica e Filosofia. Trad. Octanny Silveira da Mota e Leonidas Hegenberg. (Sâo Paulo: Cultrix. 1972.), 59. 
O que Peirce sugere é um propósito e este é o meridiano da costumeira literatura disponível sobre a participação econômica do sócio de cooperativa. O propósito intelectual dos signos consiste na totalidade dos modos gerais de conduta racional que, na dependência de todas as possíveis e diversas circunstâncias e desejos, certificam uma sincronia entre aceitação e cognição dos próprios signos.

Quero dizer, a literatura passa dos conceitos de ordem econômica para o âmbito dos signos que estabelecem uma álgebra para a gramática, isto é, só é verdadeiro, porque funcional. Em outras palavras, os significados estudados não são ideias que convocam ao pensamento, mas são as possíveis consequências nas condutas que possivelmente geram nos homens conscientes. Neste sentido, não deixa de ser um rebento (com ênfase na lógica) do Erklärung em seu sentido sincrônico (ambíguo) de declaração e explicação desde a obra de Kant e, numa genealogia, na derivação aristotélica da expressão aletheia, originalmente designação de um desvelamento, para sua identidade com a verdade. Permito-me aqui a uma pequena digressão acerca do que estou dizendo. Aletheia originalmente é o desvelamento do Beijo num bloco de mármore pela realização artística de Eugene Rodin. A técnica escultórica é a realização, ou seja, o desvelamento do Beijo para todos, porquanto já numa visão originária de Rodin para o bloco se deu a existência dele por concepção, ou seja, ainda que numa perspectiva pessoal do artista que o concebeu. Porém, num sentido de cumulação desde a sistemática aristotélica até o pragmatismo norte-americano, o Beijo só é existente, porque houve obra. A inspiração do falecido artista foi virtual, ou seja, a existência do Beijo era então potencial, e não exatamente existência pessoal. Sua existência só pode ser a sua realização, porquanto se avalia pelo resultado alcançado. Portanto, o significado do Beijo está na conduta consciente a partir da contemplação dele.

Permito-me também aqui então apresentar o que vou chamar de decadência dessa literatura (que não quer dizer degeneração e depreciação, mas quer dizer que sempre mais da mesma literatura só pode fazê-la, de algum modo, decair), socorrendo-me da Encíclica Caritas in Veritate, divulgada pelo Vaticano em 2009 (§70)28:

[I]nterrogando-se apenas sobre o como, [o homem] deixa de considerar os muitos porquês pelos quais é impelido a agir. Por isso, a técnica apresenta-se com uma fisionomia ambígua. Nascida da criatividade humana como instrumento da liberdade da pessoa, pode ser

$28 \mathrm{http} / / /$ w2.vatican.va/content/benedict-xvi/pt/encyclicals/documents/hf_ben-xvi_ enc_20090629_caritas-in-veritate.html acessado em 22 de maio de 2018. 
entendida como elemento de liberdade absoluta; aquela liberdade que quer prescindir dos limites que as coisas trazem consigo. O processo de globalização poderia substituir as ideologias com a técnica, passando esta a ser um poder ideológico que exporia a humanidade ao risco de se ver fechada dentro de um a priori do qual não poderia sair para encontrar o ser e a verdade. Em tal caso, todos nós conheceríamos, avaliaríamos e decidiríamos as situações da nossa vida a partir do interior de um horizonte cultural tecnocrático, ao qual pertenceríamos estruturalmente, sem poder jamais encontrar um sentido que não fosse produzido por nós. Esta visão torna hoje tão forte a mentalidade tecnicista que faz coincidir a verdade com o factível. (...) A técnica seduz intensamente o homem, porque o livra das limitações físicas e alarga o seu horizonte. Mas a liberdade humana só o é propriamente quando responde à sedução da técnica com decisões que sejam fruto de responsabilidade moral. Daqui, a urgência de uma formação para a responsabilidade ética no uso da técnica. A partir do fascínio que a técnica exerce sobre o ser humano, deve-se recuperar o verdadeiro sentido da liberdade, que não consiste no inebriamento de uma autonomia total, mas na resposta ao apelo do ser, a começar pelo ser que somos nós mesmos.

O que constatamos? Pelo menos uma evidência político-histórica é que essa postulação contundente da precedência da ética sobre a lógica (formal) é expressa pelo líder de um Estado teocrático e absolutista defronte a uma tendência pragmatista da relação entre os EUA e a sociedade norte-americana, paradigmática para o Direito e a Democracia.

Entre a literatura usual sobre a participação do cooperado em cooperativa e a teologia apresentada como magistério eclesiástico, proponho uma mediação de Anthony Giddens, que foi professor da London School of Economics and Political Science entre 1997 e 2003. Pelo menos, o sociólogo inglês me parece apto a mediar com habilidade a tensão criada entre esses dois gêneros literários acerca do que seja verdade na liberdade e para isso recorro à sua obra de título bem sugestivo para a decadência que ora comento: Consequências da Modernidade ${ }^{29}$.

Começo por uma curiosa frase de Popper: Toda ciência repousa sobre areia movediça ${ }^{30}$. Na análise econômica do Direito, esse movediço está implícito na teoria dos jogos. Fundamental aqui é que toda versão formalizada do real que modela a observação empírica dos comportamentos humanos está fadada a produzir informações que já demandarão a atualização dos modelos, na medida em que há necesariamente uma «reentrada» do discurso racional nos contextos em que é apli-

29 Trad. Raul Fiker. São Paulo : Unesp, 1991.

30 Karl Popper, Conjectures and Refutations (London: Routledge, 1962), 34. 
cado. No coração do mundo da vida, a ciência vagueia. Mesmo assim, insistimos em empenhos analíticos e lógico-formais, somando a nossa produção àquela que é a maior parte da informação confiável sobre um futuro programático. E que, ao fim e ao cabo, trai a própria certeza que o caracteriza. Estamos então no negativo da análise econômica do Direito: trata- se de um mundo reflexivamente representado; representação cognitiva universal em que o verdadeiro só pode ser funcional. Mas, essa representação não pode dar qualquer garantia de que qualquer elemento dado por essa universalidade não será revisado. Eis o sentido da ironia de Popper.

Sempre se quis chegar nalgum lugar. Canaã como a terra prometida é um paradigma. Mas, o pragmatismo radicaliza essa inclinação da vontade ao aplicá-lo como um (meta)princípio e como tal redutora de todos os aspectos da vida humana. O pragmatismo então é expressão de um modo próprio da modernidade, que consiste na insistência com que práticas sociais são analisadas à luz de informações sempre renovadas sobre elas próprias, alterando assim constitutivamente seu caráter ao se voltarem para si mesmas como uma autonomia, mas que já é determinável pela cognição desde antes. A vida não é a vida como ela é. É a reflexão de si mesma como ela própria programada. Em outras palavras, trata-se de uma monitoração extensiva e reflexiva da ação como uma crônica dos processos. Só que desencaixada da organização tempo-espacial de qualquer comunidade, eis que atrelada a uma plêiade de conhecimentos peritos que se refazem continuamente e assim uma crônica posta sempre para diante numa sistematização sem qualquer necessidade de encaixe local-temporal. A necessidade do pragmatismo é o próprio desencaixe. Aqui vale reproduzir o Giddens ipsi litteris:

Os sistemas peritos [sistemas de excelência técnica ou competência profissional que organizam grandes áreas dos ambientes material e social em que vivemos hoje] são mecanismos de desencaixe porque (....) removem as relações sociais das imediações do contexto. Pressupõem, embora também promovam, a separação entre tempo e espaço como condição do distanciamento tempo-espaço que eles realizam. Um sistema perito desencaixa (....) fornecendo "garantias» de expectativas através de tempo-espaço distanciados. Este «alongamento» de sistemas sociais é conseguido por meio da natureza impessoal de testes aplicados para avaliar o conhecimento técnico e pela crítica pública (sobre a qual se baseia a produção do conhecimento técnico), usado para controlar sua forma ${ }^{31}$.

31 P. 39. 
Neste contexto, há uma perturbação negativa em toda positivação promovida pelo pragmatismo (esta postulada cognição universalmente possível do comportamento humano): no limite de si, o pragmatismo trai a promessa de certeza ao distinguir risco e perigo e reduzir todo perigo ao desconhecimento dos riscos, porque não calculados, ou mal calculados. Mas antes de entrar nessa relação e sua traição, já posso oferecer seu vislumbre na permanência da reinterpretação e esclarecimento insistentes: na presença, o passado, que já está certificado, sempre vai sendo superado pelo futuro. Este, incerto, é constantemente adiado pela certificação: a morte como sonhos interrompidos.

No entanto, os sistemas peritos renovam a confiança nesse adiamento constante e neste ponto os sistemas peritos carregam um elemento pragmático de fé, baseado na experiência de que tais sistemas geralmente funcionam como se espera que eles o façam. O Direito Cooperativo se orienta pelo bem jurídico que no fundo é essa confiança que protege em favor dos cidadãos dedicados à produção e ao consumo por entre esses sistemas peritos. O Direito à guisa de garantia, promove um modo muito próprio de confiança, eis que ela está relacionada ao risco, que é ciosamente identificado entre o ilícito e o lícito. Risco é um resultado esperado, mas indesejado que é consequência potencial de nossas próprias atitudes ou decisões. Risco retrai a destinação humana. É uma desaprendizagem da morte. A confiança neste sentido demanda consciência das circunstâncias, e não das transcendências. Queremos mudanças, mas paradoxalmente queremos que as coisas permaneçam como estão. A isso, chamamos de programação ou funcionalização. Os sistemas peritos mudam o mundo todo tempo, mas o mundo que conhecemos precisa ter alguma constância. Criamos então uma expressão que é uma panaceia para esse equacionamento impossível: sustentabilidade como um modo sistemático de moderarmos os sistemas peritos entre si. Essa fé confiante que os problemas recorrentes nos processos, funções, projetos e programas se resolverão com mais processos, funções, projetos e programas é essencialmente fundada na compreensão de que a maior parte das contingências que afetam a atividade humana são de fato humanamente criadas. E aquela parte que não é humanamente criada pode ser minorada pelo crescente empoderamento humano com a própria insistência em mais processos, funções, projetos e programas paradigmaticamente expostos nos esforços de engenharia. Ou seja, a condição principal dessa confiança não é o poder humano, mas a falta de informação. Então, confiança é credibilidade em resultados que serão esperados desde que determinadas contingências sejam dadas como variáveis parametrizadas de uma função correta. Daí que a moral perde substância, porque 
a verdade e a igualdade que interessam a seu respeito se reduzem ao risco: dizem respeito ao seu funcionamento apropriado de acordo com a correção dos princípios abstratos reconhecidos ao serem (teleo)logicamente aplicados. Assim, o escopo transformador da ação humana é levado ao cabo pelo caráter dinâmico das instituições sociais modernas. Só que esse caráter dinâmico afeta a percepção da determinação e da contingência. O Direito Cooperativo é uma instituição agora voltada basicamente para um equilíbrio entre a confiança e o risco aceitável.

Mas, eis a decadência: o desencaixe - a vivência de um permanente deslocamento das relações sociais de contextos locais de interação e sua reestruturação através de distanciamentos ou ausências temporais e espaciais por especializações funcionais iniciadas desde o advento dos relógios como representações universais do tempo e dos mapa mundi como representações universais do espaço e ambos, relógico e mapa- mundo pragmaticamente considerados como marcos elementares da organização social em padrões universais.

A traição é a vivência do deslocamento como sensação vertiginosa de abandono de si mesmo, quando entregue ao eu consciente, que, tanto mais produtor de tanta segurança e controle para gáudio de todos em gozo da liberdade e da igualdade, nos lembra assustadora e insistentemente da precariedade e da temeridade que nos resta sem qualquer acolhida verdadeira e inigualável, porque retraídas de qualquer perenidade em suas transcendências: só há ausências e adiamentos. Por que? Ora, porque o inconsciente humano é... disfuncional.

\section{Um paradigma realista para a participação econômica do sócio e a gestão democrática da cooperativa}

Se a cooperativa se identifica por sua gestão democrática, a participação econômica de seu sócio vai necessariamente carregar consigo a ambivalência constante da Democracia, a saber: a presença dos governados no exercício pacífico do poder (1); o exercício conflitivo dos desejos e paixões insaciáveis de liberdade e igualdade na governança entre os governados (2). A participação econômica do sócio de cooperativa lida com essa ambivalência em que é custo de transação a sujeição das escolhas racionais aos humores na comunidade organizada em cooperativa e isso é da natureza regimental do que se diz democracia.

Demonstro o meu comentário pelo método de caso. A Aliança Cooperativa Internacional, em Nov/2017 publicou um material institucional denominado A matter of principle: Co-operatives in develop- 
ment ${ }^{32}$. O material se reveste de objetividade num evidente esforço de comunicação global. E ao fazê-lo, bosqueja narrativas realistas, eis que apresentadas como algo que vai sendo informado de passagem ${ }^{33}$. O texto insinua as narrativas pela mimese entre inscrição e visão dos fatos dados. No texto, o que se visualiza é o real. O que há entre o real e o realismo? Uma escolha que se mostra na visão que não visa o que poderia ser. Visa o que só pode, porque já é. O que já é, é consumado. Sobre o consumado, se exerce domínio. Aqui, o seu empoderamento sobre a insaciedade pelo que a democracia flerta perigosamente com a vontade de potência. Toda combinação realismo/idealismo retrai no inscrito a vontade presente em qualquer descrição. Quero dizer, quais são os sentidos possíveis do que não foi descrito numa descrição realista? Esta é a realização do real no realismo, porque o realismo visa o realizado, e não a realização. No lugar da realização, impera o procedimento.

32 https://www.ica.coop/en/media/library/a-matter-of-principle-co-operatives-in-development acesso em 23 de maio de 2018.

33 «The Federación Uruguaya de Cooperativas de Vivienda por Ayuda Mutua (FUCVAM), allows low income locals to have access to dignified and durable housing, a model that has already expanded to 15 countries in Latin America, and includes other amenities such as community farms or day care» (p. 9) «The Co-operative Alliance of Kenya (CAK) ensures that there are elections every year, presenting an enabling environment for effective participation where each member has a right to speak in meetings and stand for any elective position in the co-operative» (p. 10) «In Kerala, the Uralungal Labour Contract Co-operative Society started way back in 1925 for the benefit of 14 marginalised labourers who lost their livelihood due to their active participation in Indian Freedom Movement. Today, they are the leading co- operative society in the country uplifting standard of living of over 5.000 workers directly contributing to the development of the society» (p.11) "Caminos (Roads) is a Uruguayan Co-operative formed by a group of mainly female health professionals in 2002 when the mutual for which they worked closed. Currently, Caminos provides quality employment to more than 100 people committed to selfmanagement.» (p.12) «Moshi Co-operative University (MoCU) is the oldest training institution in Tanzania, and it's committed to the promotion of equal opportunities and constructive involvement in community development. Current university enrolment stands at more than 4.000 students in the fields of co-operative accounting, management, and rural development.» (p.13) «In 2010, Palestinian farmers in Jordan Valley decided to make their co-operatives work together to overcome the region's restrictions on movement and access to resources, markets, and services. The Seedling Nursery in Jordan Valley now is run by three different co-operatives: The Northern Jordan Valley Agriculture Co-operative, Ein Al Beda Agriculture Co-operative and Al Khadra Agriculture Co-operative, whose 245 farmers benefit from the nursery's quality, prices, and seed compatibility.» (p.14) «In Mexico, since 2008, "Caja Popular Mexicana», a savings and credit co-operative, has been running a big program of social responsibility for their 2 million members. Their scholarship program has benefited over 56.000 students. » (p.15). 
O que quero enfatizar aqui? A participação econômica do sócio de cooperativa já é o que disso se espera. Eis que seu fim já está dado desde antes do seu escrever. O imaginário desse fim programático encontra sua expressividade como desenvo/vimento na publicação da $\mathrm{ACl}$ aqui comentada. Mas, se Democracia é gestão da vontade de potência pela vontade de verdade, uma linguagem realista do real, como qualquer outra, sempre esconde tanto quanto mostra. E o que esconde, é escondido pelo que mostra: uma totalidade ilusória do real. Porque realismo não é somente realidade mostrada; é também uma linguagem. Portanto, uma realização. Uma, dentre possíveis realizações. Aqui me concilio com essa literatura: mantenho a sua visada na alternância de poder. Também aqui o traio por não assumí-la como natureza da democracia. $E$, sim, como aquilo dela que é além do natural. É um platô; um lineamento; uma cartografia.

Assumindo como linguagem o que a literatura da $\mathrm{ACl}$ nos inscreve na perspectiva de uma quarta parede, a diferença num conjunto conceitual oculta a oscilação vivenciada para se mostrar como uma questão de certeza e previsibilidade. Certeza é muito desejada pela Aliança Cooperativa Internacional. Então, para um regime democrático, tanto melhor quando seu devir é visado mais pelos interesses e menos pelos desejos. O interesse sobrecarrega de faticidade o horizonte visado pela literatura em seu primeiro plano. O desejo, neste plano, se mostra numa governança como retração das paixões brutais, quando manifestas entre os governados. Carregando o desejo algum sentido de presença da falta, há num desejo sempre algo em jogo de atração e retração. Há algo de desejável em qualquer ideal que não seja só formal, ou seja, pura função. Na urbe, ressignificada assim resta a via direita em face ao sinistro. Num sentido de engenhosidade que aproxima política da arquitetura.

Sob a influência da principiologia emanada da $\mathrm{ACl}$, em que pesem muitas nuances possíveis acerca da correlação entre participação econômica do sócio da cooperativa e sua gestão democrática, a sombra de Kant as unirá na possibilidade de uma sinopse sistemática, crítica, totalizante e autônoma de qualquer cosmovisão metafísica.

O transcendental kantiano culminou no idealismo alemão de Fichte, Schelling e Hegel. Particularmente em Schelling, o idealismo e o romantismo convergem na experiência estética. Sabemos igualmente que o pragmatismo é uma vertente de pensamento originário entre o utilitarismo anglo-saxão e o racionalismo francófono em tensão com o idealismo e o romantismo alemães. Para isso, cria uma linguagem que prescinde da subjetividade transcendental. Essa oposição, de certo modo, foi superada com o historicismo hegeliano. Essa superação en- 
contra em Habermas uma expressão contemporânea bem conhecida que reafirma esse projeto totalizante, crítico e epistêmico da razão que tem sido perseguido desde Kant.

Mas, também sabemos que o projeto da razão na obra de Hegel foi colocado em xeque por Schopenhauer, Kierkegaard e Nietzsche. Em Nietzsche, a liquidação do projeto totalizante da razão tem lugar na estética da expressividade. Essa liquidação, em particular, alcança Kant em A Genealogia da Mora/34, cuja repercussão contemporânea mais influente se encontra na obra de Foucault.

A vontade não está necessariamente sujeita ao encontro de meios adequados aos fins dados pela razão (a máxima da moral). Na ética compreendida por Foucault, só se toma consciência do fim no meio dos meios - a arqueologia do saber e a genealogia do poder. Através de Foucault, Niestzsche é decisivo. Não como Kant. Não há métrica possível. Mas, nem por isso, indecidível.

O Direito Cooperativo é assombrado por Kant, quando a normalidade da democracia assume a cena diante da quarta parede em que inscreve o lugar do leitor; Foucault é assombrado por seu duplo que não é par, Nietzsche, quando é qualquer outra margem que situa o texto. A quarta parede se dissolve na arena. Em todo caso, a circunstância permanece na linha de frente: não há essência ou substância a ser buscada em quaisquer dos textos, somente a sua história.

Não quero seguir comentando a obra de Focault em contraponto à publicação $A$ matter of principle à guisa de paradigma exposto pelo método de caso. Mas, sim um par seu. Quiçá mais brutal. Brutalidade que dá oportunidade de demonstrar em poucas linhas um outro texto que se encontra retraído naquela publicação paradigmática. Estou falando de um membro do famoso Grupo de Informação sobre as Prisões que impactou indelevelmente a Democracia desde 1968. Eu falo de Deleuze.

\section{Uma esquizoanálise do paradigma}

Deleuze escreveu a quatro mãos com Guattari a obra Mil Platôs, que traz o subtítulo Capitalismo e Esquizofrenia 2. É o $5 .^{\circ}$ volume da obra que escolhi como contraponto ao paradigma principiológico entre a participação econômica do cooperado e a gestão democrática da cooperativa exposto a partir da publicação da $\mathrm{ACl} A$ matter of princi-

34 3. ${ }^{a}$ Ed. Trad. Antônio Carlos Braga. (São Paulo:Escala, 2009). 
ple: Co-operatives in development ${ }^{35}$. Porque se extrai de Mil Platôs um pragmatismo nômade, em contraste ao pragmatismo continente da tradição anglo-saxã.

O que Nise da Silveira pela obra de arte encontrou na esquizofrenia ${ }^{36}$ ? Que um padrão é possível mesmo desprovido de funcionalidade. Possibilidade que não parece suscitar mais polêmicas em qualquer debate sobre estética. Não é acaso que bancos costumam patrocinar exposições de arte contemporânea. Na ausência de funcionalidade, um outro caminho é possível no meio do caminho entre a existência humana e a banalidade usual. De algum modo, esse padrão sem função foi apreendido em palavras por Guattari. E com Deleuze, um sistema conceitual que prescinde de funções foi inscrito na política. Sendo sistema, há lineamentos vários que obedecem uma lógica, mas não há trajetória. A principiologia da $\mathrm{ACl}$ tende à vontade de verdade pela naturalização do tempo. Natural é aquilo dizível sujeito a uma determinação. O tempo é naturalmente um agora entre um antes e um depois: trajetória histórica num desenrolar em determinação de resultados esperados, inesperados ou temidos. Em Mil Platôs, a linguagem criada mostra uma sistemática, mas desnaturaliza o tempo, porque prescinde de qualquer cronologia. Ao fazê-lo, propõe uma cartografia, mas, ao mesmo tempo, desterritorializa o pensamento em circunstâncias diversas. Há platôs, mas não territórios predefinidos para o pensamento. Não há uma rota traçada para dizer da participação econômica do cooperado e a gestão democrática da cooperativa. O que uma esquizoanálise mostra então? Nem o natural, nem o migrante. Entre identidades e diferenças de um e outro, fora desse continente, aparece o nômade, um ser assimétrico para qualquer das transições circunstanciais em que se põem o natural e o migrante.

Em perspectiva, essa assimetria do nômade faz aparecer o que a simetria dos atores racionais que se pressupõe usualmente partícipes econômicos da cooperativa: fulgura, apesar de todos os medos de falência da democracia, sua irrupção criativa. No meio do seu caminho, entre identidades e diferenças de um conjunto de conceitos em percurso normativo, há, nem sempre notado, um terceiro excluído.

Hoje, a gestão democrática da cooperativa agrega valor por sua responsividade, quando conciliada com a participação econômica do sócio de cooperativa e esta vai pensada como resultado dos interesses, incentivos e expectativas. Conforme uma visão de materializar na

35 Ver nota 31.
36 Imagens do Inconsciente. (Petrópolis:Vozes, 2015).

Boletín de la Asociación Internacional de Derecho Cooperativo 
pessoa do cooperado os conceitos de proprietário/investidor e usuário/ beneficiário da cooperativa. Isto é, uma cidadania que suporte um sentido de satisfação por consumação. A cidadania se torna dispositiva. É o sentido da expressão «escolha» para sintetizar em uma palavra o contexto tempo-espacial da cooperativa. Isto é, performance é um acontecimento que se pretende apropriativo da relação cooperativacooperado. Seu propósito é superar a dicotomia entre o atendimento personalizado e o de larga escala. São estas variáveis consideradas decisivas para a competitividade em mercados marcados pela intensificação do capital e aumento de escala. O sucesso de uma gestão democrática se traduz no manejo próprio de ferramentas de gestão e governança para a integração entre tecnologias e processos negociais. Integridade que objetiva a satisfação ótima do cooperado durante qualquer interação dada.

O maior problema para a gestão democrática da cooperativa se dá na própria superposição das condições de usuário e "dono-investidor» cooperativa. No caso da atividade empresarial, um usuário/consumidor não é responsável pelos processos operacionais. Trata-se de uma fatoração de risco para o negócio. Mas o cooperado tem um papel diferente na interação no que se refere ao sentido de pertencimento a uma comunidade. Para com a iniciativa privada, o pertencimento se manifesta no consumo ambientalmente sustentável e socialmente responsável. Mas, para com a cooperativa, se manifesta como co-responsável pelo próprio dispositivo. Enquanto o processo produtivo tende a eliminar comportamentos disfuncionais pelo darwinismo empresarial proporcionado pela concorrência nas economias de mercado, o mesmo não acontece tão naturalmente assim entre os cooperados. Ou seja, pela interação individual maior dos cooperados na gestão, as cooperativas restam potencialmente mais vulneráveis aos comportamentos disfuncionais. Então a saturação democrática se apresenta como um risco para a governança. Esse risco é bosquejado pela linguagem realista, quando se aborda as oportunidades e forças de uma gestão qualificada.

Em meados dos anos 80, emergiu da gestão de empresas japonesas o conceito de qualidade que deixou de remeter aos atributos reais do produto (por exemplo, durabilidade e beleza) para se referir aos atributos relacionais da produção: qualidade é satisfação. Em termos de gestão, a ênfase foi dada ao empoderamento das variáveis endógenas e exógenas do processo produtivo: o objetivo prático de toda gestão é a minimização de erros e atrasos pela adoção de padrões procedimentais orientados no atendimento ao que é requerido desde antes do processado. As certificações ISO 9000 são paradigmáticas nessa mudança conceitual da qualidade. 
Gestão qualificada é um conceito próprio da saturação eletrônica vivida pelo setor industrial no pós guerra. Na virada do Século XXI, no setor alimentício, a gestão qualificada passa a integrar em si mesma a tecnologia da informação: surge então a ideia de qualidade como empoderamento da interatividade de diferentes agentes da cadeia produtiva. Mas, dada a limitação da TI à época, essa noção de qualidade por interação estava voltada à dinâmica física da agilidade proposta: a logística. Os efeitos foram significativos: intensificação de capital e ganhos de escala operacional com eficiências agregadas - houve uma disrupção. Agora, ocorre uma amplificação em termos da performance a todas as dimensões dinâmicas de relacionamento da cadeia produtiva por um processamento tecnológico de informação massiva. Tem o consumidor individualmente considerado como referência, porque advém da gestão qualificada o paradigma da padronização dos procedimentos no atendimento ao que é requerido desde antes do processado: a performance focada na satisfação como resultado perseguido. Há a ampliação da possibilidade de satisfação com a aquisição da capacidade de customização ao nível individual da operação em escala pelo processamento de dados massivos acerca do consumidor e interação em tempo real com ele. A padronização não alcança mais ao produto disponível. Ela se dá no processamento para chegar ao produto. A indústria automobilística de alta performance foi pioneira nessa agregação de valor: A Ferrari é um paradigma por demais conhecido. É um paradigma de que todo produto é dispositivo desde antes de sua realização. A Apple levou esse paradigma à sua culminância de escala e alcance. Lipovetsky chama isso de diversificação proliferante e escalada do efêmero ${ }^{37}$. O Smartphone é ícone global desse fenômeno.

Tentador então propor uma cooperativa igualmente artista. É o que, por exemplo, a Organização das Cooperativas Brasileiras propõe, quando inscreve como sua visão institucional: «Em 2025, o cooperativismo será reconhecido pela sociedade por sua competitividade, integridade e capacidade de promover a felicidade dos cooperados» ${ }^{38}$. O empoderamento empresarial é amplificado para um empoderamento instrumental, processual e tecnológico disponível ao cooperado individualmente considerado numa amálgama mais aprofundada entre individualismo e pessoalidade. Trata-se de um transbordamento, de uma saturação da diversificação e do imediato para as políticas institucio-

37 Gilles Lipovetski e Jean Serroy, A estetização do Mundo. Trad. Eduardo Brandão. (São Paulo:Companhia das Letras, 2015), 52-56.

38 http://www.ocb.org.br/arquivos/MapaEstrategico/final_mapa_estrategico_ sistema_21_09.pdf acessado em 23 de maio de 2018. 
nais de bem estar. Evidentemente, um modelo que só se torna possível pelo emprego da tecnologia da informação em rede e em larga escala, isto é, marcado pela máxima agilidade performática. Interessa menos o que se presta ao cooperado. Desde que seja ágil e imediato responder à sua demanda e responder o mais segmentado possível ao seu perfil de hábitos, garantido o seu bem estar na satisfação tão rápida como fácil das suas escolhas habituais. A repetição da sensação de satisfação dos cooperados é o sentido de felicidade buscada pelos esforços qualificados, corretos e eficientes (capacidade, integridade e competitividade).

Mas, eis que avulta o sentido trágico da existência nas disfunções do inconsciente! De algum modo, a consumação da cooperativa visada pela OCB aprofunda a consumição do cooperado: é o paradoxo de um bem-estar bulímico. Eis o paradoxo: sendo o ato de consumir o acontecimento apropriativo de uma época, o bem estar é perseguido a custa de uma insatisfação permanente por uma retroalimentação incessante de expectativas. Uma vez focada a cidadania na funcionalidade, sem a busca em algum sentido de felicidade além da satisfação, a existência da cooperação perde qualquer sentido além da funcional. E a ansiedade se manifesta como uma pandemia.

Ansiedade pandêmica se dá, quando muitos sentidos de satisfação são possíveis pela multiplicação de dispositivos persecutórios. O empoderamento do cooperado se mostra limitado num excesso de opções que não podem ser vivenciadas sem uma abdicação penosa de umas em favor de outras. Como abrir mão? Como se conter? Como se conformar? Como não se ressentir? Como se satisfazer, se outra satisfação é incessantemente prometida? A culminância da cooperativa é a culminância da desumanização no fetiche de um humanismo programático e pragmático. Paradoxo manifesto na figuração dos mortos agitados e aglomerados às portas de um shopping center - cena alegórica contextual de A Madrugada dos Mortos 39 . Nem os mortos descansam mais. Nem mesmo às portas de suas co-operativas.

39 Filme de 2004, dirigido por Zack Snyder produzido pela Strike Entertainment em associação com a New Amsterdam Entertainment, e distribuído pela Universal Pictures. É um remake de um filme homônimo de 1978, dirigido por George Romero, que transpôs para um contexto cosmopolita a alegoria inicialmente proposta por ele (1968, em A noite dos mortos-vivos) para retratar a incerteza como terror absoluto no imaginário dos americanos sulistas anglo-saxões forçados à integração racial com os efeitos do decidido pela Suprema Corte sobre direitos civis e implementada pelo poder público federal. De 1978 a 2004, a mais significativa mudança realizada na alegoria foi a performance dos mortos. Em 2004, eles estão frenéticos. 


\section{5. À guisa de conclusão}

Ora, uma esquizonálise não conduz um texto à sua conclusão. Então o que pode vir a ser escrito à guisa de conclusão deste? Que resta uma questão aberta no potencial das práticas de cooperação na ordem econômica pela adoção de ferramentas de gestão que incrementem uma maior interação entre a administração da cooperativa e os cooperados a partir dos padrões atuais de satisfação. Posto na contemporaneidade em seu limite de culminância, a insistência no projeto de satisfação está cada vez mais marcada pela hiperatividade performática-produtiva. Ela está assentada em quatro pilares: (K) o capital desterritorializado; (C) a consumerística estética, experiencial e satisfativa; (I) a individualidade desdefinida e transvazada; e a (T) tecnociência imperial.

De certo modo, Foucault, ao anunciar que viveríamos um século deleuziano, parece que foi despropositadamente profético. Foucault a inscreveu o vaticínio em 1970 no artigo Theatrum Philosoficum, publicado na revista Critique, repercutindo dois livros de Deleuze: Diferença e repetição e Lógica do sentido ${ }^{40}$.

O século deleuziano pode ser entendido como uma inesperada conjugação entre a razão instrumental e a pragmática nômade nos pilares KCIT. Esta conjugação teve um enredamento: a filosofia como criação de conceitos, e não como lógica comunicativa. O conceito é o acontecimento, e não sua apresentação. Ambas, a razão instrumental e a pragmática nômade, quando enredadas, se tornam radicalmente circunstanciais e demolidoras de qualquer preocupação com a finalística. É essa despreocupação que se retrai na expressão felicidade. Essa expressão é signo da despreocupação. O fim já está dado, ou ainda não interessa. O enredamento é a intersubjetividade como um mapa de circunstâncias que são os modos de individuação tanto de coisas como de pessoas, mas não é preciso definir nem as pessoas nem as coisas. A conjugação é uma cartografia que prescinde de territorialidade. Ou uma narrativa que prescinde da crônica:

O Estado arcaico não sobrecodifica sem liberar também uma grande quantidade de fluxos descodificados que vão lhe escapar. Lembremos que "descodificação» não significa o estado de um fluxo cujo código seria compreendido (decifrado, traduzível, assimilável) mas, ao contrário, num sentido mais radical, o estado de um fluxo que não é mais compreendido dentro de seu próprio código. (....) A

40 Gilles Deleuze. Conversações. Trad. Peter Pál Pelbart. 3. ${ }^{\text {a } . ~ e d . ~(S a ̃ o ~ P a u l o: E d i t o r a ~}$ 34, 2013), 115. 
questão vem a ser portanto: há gente que seja constituída no império sobrecodificante, mas constituída como excluída e descodificada necessariamente? (....) o escravo liberto. É ele quem não tem mais lugar. É ele quem lança suas lamentações por todo o império (....): a queixa (elegia) foi sempre fator político. (....)

O que conta (....) não é o caso particular do escravo liberto. $O$ que conta é o personagem coletivo do Excluído. O que conta é que, de uma maneira ou de outra, o aparelho de sobrecodificação suscita fluxos eles mesmos descodificados - de moeda, de trabalho, de propriedade... estes são o correlato daquele ${ }^{41}$.

Se «a lógica de um pensamento é o conjunto das crises que ele atravessa, assemelha-se mais a uma cadeia vulcânica do que a um sistema tranquilo e próximo do equilíbrio» ${ }^{42}$, há lógica em afirmar que, na felicidade visada pela OCB, a hiperatividade se evidencia como o mal do século. Porque, sendo uma cooperativa competitiva sobre os pilares KCIT, se estrutura uma realização entre a proliferação do diverso e a escalada do efêmero. Se a cooperativa é vista como capaz de promover a felicidade de seus cooperados, é porque, de certo modo, nela não há mais lugar para os degredados filhos de Eva ${ }^{43}$.

Tanto a gestão democrática da cooperativa como a participação econômica do cooperado, quando visadas para a perseguição da felicidade, convergem numa normalidade que dilata e incorpora ao seu programa a celebração máxima da criatividade, mobilidade, autenticidade, motivação, engajamento e autodeterminação formatadas pela obsessão por performance e inovação. A razão instrumental e a pragmática nômade convergiram na hiperatividade produtiva de impressões sensíveis e emocionais como sentido da consumerística cada vez mais experiencial da satisfação e, por isso mesmo, bulímica e sempre ansiosa, o que se afirma como dignidade humana numa individuação que se desdefine continuamente pelo vazamento recorrente das formas estabelecidas. Ora, a razão instrumental e a pragmática nômade lograram a subordinação da ética à estética! Por que? Simplesmente, porque funciona em uma retroalimentação cuja única constância é a aceleração

41 Gilles Deleuze e Felix Guattari. Mil Platôs. Vol. 5. Trad. Peter Pál Pelbart, Janice Caiafa. (2. ${ }^{a}$. Ed. São Paulo: Editora 34, 2012), 155-157.

42 DELEUZE. Conversações... p. 110.

43 Salve, Regina, Mater misericordiae/Nita, dulcedo, et spes nostra, salve/Ad te clamamus, exsules filii Hevae/Ad te suspiramus, gementes et flentes/In hac lacrimarum valle/Eia, ergo, advocata nostra/ illos tuos misericordes oculos ad nos converte/Et Jesum, benedictum fructum ventris tui, Nobis post hoc exilium ostende/O clemens, $O$ pia, O dulcis Virgo Maria/N.: Ora pro nobis sancta Dei Genetrix/R.: Ut digni efficiamur promissionibus Christi. 
de seu acontecimento: uma fazeção performática que é o próprio significado corrente de sustentabilidade - expressão síntese de uma pragmática superaquecida. O capital, que já foi atraído para as matérias-primas, depois sucessivamente para o produto e para o serviço, agora é atraído para a experienciação.

A felicidade do cooperado assim visada só pode corresponder a um único sentido: assegurar-se em não sofrer senão por vontade própria. $E$ isto corresponde a processos que excretam satisfação, ainda que efêmera, mas por isso mesmo cada vez mais exigível com o poder crescente proporcionado pela tecnociência e a intensificação do capital desterritorializado. Aqui, o sublime vigora como criação ininterrupta de sentidos que escapam da totalização num projeto da razão, que portanto só pode subsistir em abertura à profusão da diversidade que é correlato da individuação extrema. Ou ele é epifântico, ou espetacular. Mas, uma epifania é o descanso do espírito e, como tal, essencialmente improdutiva: ela é contemplativa. Resta o espetáculo. Este é produtivo. Este, sim, é funcional. Então, a cooperativa está condenada à hiperatividade performática. Porque vivemos uma infla(ma)ção estética: descentralizada, desierarquizada, eclética, gelatinosa, fragmentária, vazada de formas, híbrida, superposta, transgênero e heteróclita. Tudo isso reivindicado e generalizado como Direito Cooperativo: uma normatização estatal de um modo específico para a busca frenética pela felicidade ${ }^{44}$ ! E o globo, com as cooperativas nele, cada vez mais vai se tornando um grande bazar caleidoscópico ${ }^{45}$.

\section{Referências bibliográficas}

ALIANZA COOPERATIVA INTERANCIONAL, Notas de Orientación para los principios cooperativos. 2015. Acessado em 22 de maio de 2018, https://ica. coop/sites/default/files/publication-files/guidance-notes-es-2107251738. pdf

ARANA LANDÍN, Sofía. 2018. "The scarcity of worker cooperatives in the USA: enquiring into possible causes». CIRIEC-España, Revista de Economía Pública, Social y Cooperativa, núm. 92, pp. 33-60.

BELLO, Angela Ales. 2004. Trad. Miguel Mahfoud e Marina Massimi. Fenomenologia e ciências humanas. Bauru: Editora da Universidade do Sagrado Coração.

CAMPOS SAAVEDRA, Luis F.; RODRÍGUEZ MORILLA, Carmen. 2017. "Los bienes democráticos en la economía del bien común: cuatro vías para su deli-

\footnotetext{
44 Saul Tourinho Leal, Direito à felicidade (São Paulo:Almedina, 2017).

45 Gilles Lipovetski e Jean Serroy. A estetização..., 53.
} 
mitación conceptual». CIRIEC-España, Revista de Economía Pública, Social y Cooperativa, núm. 90, pp. 223-252.

CARRERAS ROIG, Lluis; BASTIDA VIALCANET, Ramón. 2015. «Estudio sobre la rendición de cuentas en materia de responsabilidad social: el balance social». CIRIEC-España, Revista de Economía Pública, Social y Cooperativa, núm. 84, pp. 251-278.

DELEUZE, Gilles. 2013. Conversações. Trad. Peter Pál Pelbart. 3. ${ }^{a}$ ed. São Paulo: Editora 34.

DELEUZE, Gilles; GUATTARI, Felix. 2012. Mil Platôs. Vol. 5. Trad. Peter Pál Pelbart, Janice Caiafa. 2. ${ }^{a}$ Ed. São Paulo: Editora 34.

GÓMEZ CALVO, Verónica; GÓMEZ-ÁLVAREZ DÍAZ, Rosario. 2016. «La economía del bien común y la economía social y solidaria, ¿son teorías complementarias?». CIRIEC-España, Revista de Economía Pública, Social y Cooperativa, núm. 87, pp. 257-294.

GOYARD-FABRE, Simone. 2007. Os fundamentos da ordem jurídica. Trad. Claudia Berliner. São Paulo: Martins Fontes.

ICA, acessado em 23 de maio de 2018, https://www.ica.coop/en/media/library/ a-matter-of-principle-co-operatives-in-development

LEAL, Saul Tourinho. Direito à felicidade. São Paulo: Almedina, 2017. LIPOVETSKY, Gilles; SERROY, Jean. A estetização do Mundo. Trad. Eduardo Brandão. São Paulo: Companhia das Letras, 2015.

LYOTARD, Jean-François. Libidinal Economy. Trad. Iain Hamilton Grant. Bloomington: Indiana University Press, 1993.

ORGANIZAÇÃO DAS COOPERATIVAS BRASILEIRAS, acessado 22 de maio de 2018, http://www.ocb.org.br/arquivos/MapaEstrategico/final_mapa_ estrategico_sistema_21_09.pdf acesso em 22.05.2018

ONATE, Alberto Marcos. Entre eu e si ou a questão do humano na filosofia de Nietzsche. Rio de Janeiro: 7 Letras, 2003.

PEIRCE, Charles Sanders. 1972. Semiótica e Filosofia. Trad. Octanny Silveira da Mota e Leonidas Hegenberg. Sâo Paulo :Cultrix.

POPPER, Karl. 1962. Conjectures and Refutations, London: Routledge.

SARTRE, Jean-Paul. 2008. A imaginação. Trad. Paulo Neves. Porto Alegre: L\&PM. SILVEIRA, Nise. 2015. Imagens do Inconsciente. Petrópolis:Vozes.

VATICAN, acessado em 22 de maio de 2018, http://w2.vatican.va/content/ benedict-xvi/pt/encyclicals/documents/hf_ben-xvi_enc_20090629_caritasin-veritate.html 


\section{Derechos de autor}

El Boletín de la Asociación Internacional de Derecho Cooperativo es una revista de acceso abierto lo que significa que es de libre acceso en su integridad inmediatamente después de la publicación de cada número. Se permite su lectura, la búsqueda, descarga, distribución y reutilización legal en cualquier tipo de soporte sólo para fines no comerciales y según lo previsto por la ley; sin la previa autorización de la Editorial (Universidad de Deusto) o el autor, siempre que la obra original sea debidamente citada (número, año, páginas y DOI si procede) y cualquier cambio en el original esté claramente indicado.

\section{Copyright}

The International Association of Cooperative Law Journal is an Open Access journal which means that it is free for full and immediate access, reading, search, download, distribution, and lawful reuse in any medium only for non-commercial purposes, without prior permission from the Publisher or the author; provided the original work is properly cited and any changes to the original are clearly indicated. 